\title{
Exploratory cohort study and meta-analysis of BIM deletion polymorphism in patients with epidermal growth factor receptor-mutant non- small-cell lung cancer treated with epidermal growth factor receptor tyrosine kinase inhibitors
}

This article was published in the following Dove Press journal:

OncoTargets and Therapy

3 April 2017

Number of times this article has been viewed

\author{
Si Sun ${ }^{1,2}$ \\ Hui Yu ${ }^{1,2}$ \\ Huijie Wang ${ }^{1,2}$ \\ Xinmin Zhao ${ }^{1,2}$ \\ Xintai Zhao ${ }^{3}$ \\ Xianghua $\mathrm{Wu}^{1,2}$ \\ Jie Qiao ${ }^{1,2}$ \\ Jianhua Chang ${ }^{1,2}$ \\ Jialei Wang ${ }^{1,2}$ \\ 'Department of Medical Oncology, \\ Fudan University Shanghai Cancer \\ Center, ${ }^{2}$ Department of Oncology, \\ Shanghai Medical College, Fudan \\ University, ${ }^{3}$ Shanghai Shines \\ Biomedical Co. Ltd., Shanghai, \\ People's Republic of China
}

Background: Non-small-cell lung cancer (NSCLC) patients with epidermal growth factor receptor $(E G F R)$ mutations might develop primary and secondary resistance to tyrosine kinase inhibitors (TKIs). The proapoptotic protein Bcl-2-like 11 (BIM) is a key modulator of apoptosis triggered by EGFR-TKIs. The recent studies have indicated that some patients with positive EGFR mutations were refractory to EGFR-TKIs if they harbored a BIM deletion polymorphism. The purpose of this study was to investigate whether BIM polymorphism predicts treatment efficacy of EGFR-TKIs in Chinese NSCLC patients.

Patients and methods: A cohort of advanced NSCLC patients with EGFR mutations and treated with EGFR-TKIs (gefitinib or erlotinib) were recruited. We drew peripheral blood to determinate $B I M$ deletion status and then compared patients' clinical outcomes according to the BIM deletion status. Additionally, we electronically searched eligible cohort studies and conducted a meta-analysis to pool event risk.

Results: The exploratory cohort study included 140 patients. Patients with and without the BIM deletion polymorphism had similar objective response rates (ORRs, 48.5 vs $63.0 \%, P=0.16$ ), disease control rate (DCR, 93.9 vs $97.0 \%, P=0.60)$ and adverse reactions. Similar progressionfree survival (PFS) and overall survival (OS) were noted in overall population $(P=0.27$ for PFS and $P=0.61$ for OS) and prespecified patient subgroups. The meta-analysis included 10 eligible cohort studies involving 1,317 NSCLC patients. It showed the positive BIM deletion was associated with shorter PFS (hazard ratio $=1.45 ; P=0.02$ ). Nonsignificant differences existed for ORR, DCR and OS.

Conclusion: The expanded meta-analysis results demonstrated the positive BIM deletion predicts shorter PFS in NSCLC patients after treatment with EGFR-TKIs while other clinical measures do not. A large multicenter well-designed cohort study involving other concurrent genetic alterations is warranted.

Keywords: BIM, EGFR, NSCLC, clinical outcome

\section{Introduction}

Non-small-cell lung cancer (NSCLC) is the leading cause of cancer-related death. ${ }^{1}$ Like other cancers, NSCLC develops when cells initiate to uncontrollably drive mutations due to changes in their genes. Using targeted therapies could specifically attack 
these changes and block the growth of cancer cells without damaging the normal cells like cytotoxic chemotherapy. ${ }^{2}$ The representative targeted therapy - tyrosine kinase inhibitor (TKI), which targets mutated epidermal growth factor receptors (EGFRs) - has turned into a better alternative for treating advanced NSCLC. ${ }^{3}$ Consequently, it has surprisingly changed the treatment of advanced NSCLC. ${ }^{4-6}$ NSCLC patients with $E G F R$ mutations who receive first-line therapy with an EGFR-TKI, such as gefitinib or erlotinib, have longer progression-free survival (PFS) than those who are treated with platinum-based chemotherapy. ${ }^{4,7-9}$ However, about $30 \%$ of these patients show primary resistance to EGFRTKIs even if they have EGFR mutations; meanwhile, most patients who respond initially might acquire drug resistance after approximately 1 year of treatment.,5,9-11 Mechanisms of acquired resistance to EGFR-TKI include T790M secondary mutation, or subsequently C797S mutation responsible for resistance to T790M-targeting EGFR inhibitors, and MET amplification. ${ }^{12-14}$

$B I M$, also known as Bcl-2-like 11 (BCL2L11), is a member of the Bcl-2 family of genes and encodes the protein BIM. By binding to all members of the prosurvival Bcl-2 subfamily with high affinity, BIM serves as a key element in promoting apoptosis. BIM deletion polymorphism is a 2,903-bp deletion located in exon 2 of the BCL2L11 gene that leads to alternative splicing of the mRNA of $B I M$, which results in expression of $B I M$ isoforms lacking the pro-apoptotic BCL2-homology domain 3 (BH3). ${ }^{15}$ It is hypothesized that BIM might be involved in the apoptotic signaling following EGFR disruption by TKIs. ${ }^{2}$ The intrinsic resistance and incomplete response may be due, in part, to downregulation of BIM expression. ${ }^{11,12}$ A recent study has suggested that the BIM germline alteration would prevent apoptosis induced by EGFR-TKIs, which poses a potential mechanism conferring resistance. ${ }^{16}$ Another study has showed that BIM deletion polymorphism is associated with primary drug resistance to EGFR-TKIs. ${ }^{17}$ As shown by induction of apoptosis, the EGFR-mutant NSCLC cells with the BIM deletion polymorphism are much less sensitive to gefitinib than those with wild-type $B I M .{ }^{15}$ Thus, therapies that upregulate BIM expression, such as histone deacetylase inhibitor, vorinostat, may resensitize some low BIM-expressing oncogene-addicted cancers to targeted therapies. ${ }^{17}$

Given that EGFR-mutated lung tumors occur more frequently in East Asians and the BIM polymorphism is also prevalent in East Asian population and seldom found in Caucasian counterparts, ${ }^{16}$ we carried out this exploratory cohort study in the People's Republic of China to investigate the predictive role of $B I M$ deletion polymorphism in advanced EGFR-mutant NSCLC patients treated with EGFR-TKIs. Besides, we sought to perform a meta-analysis incorporating all currently available evidences from cohort studies to compare the clinical outcomes according to the $B I M$ polymorphism status in NSCLC patients with EGFR mutations after the treatment with EGFR-TKIs.

\section{Patients and methods}

\section{Patients}

In this exploratory cohort study, a total of 140 NSCLC patients harboring EGFR mutation who were treated with EGFR-TKIs were recruited from June 2009 through May 2013. This study was approved by the Ethics Committees of Shanghai Cancer Center, Fudan University, and was carried out in accordance with the World Medical Association's Declaration of Helsinki (1964) and its later amendments. Informed consent was obtained from each participating patient before any study-related procedure was performed.

Patients received either oral gefitinib (250 mg per day) or oral erlotinib (150 mg per day). Every 2 months, patients were assessed for response using Response Evaluation Criteria in Solid Tumors (RECIST) version 1.1. ${ }^{18}$ According to this criteria, overall response rate (ORR) was defined as the proportion of patients who had complete response and partial response, while disease control rate (DCR) was defined as the proportion of patients who had a best response rating of complete response, partial response or stable disease. PFS was calculated from the date EGFR-TKIs therapy was initiated to the date of either tumor progression or death from any cause. Overall survival (OS) was defined as the time from the initiation of EGFR-TKIs therapy to death from any cause. Adverse events related to EGFR-TKIs treatment were evaluated using the National Cancer Institute Common Terminology Criteria for Adverse Events (NCI CTCAE) Version 4.0 (2009).

\section{EGFR mutations and BIM deletion polymorphism}

We used direct sequencing to determinate EGFR (exons 18-21) mutations in polymerase chain reaction (PCR) fragments amplified with genomic DNA from formalin-fixed paraffin-embedded tissue. ${ }^{19,20}$ BIM deletion polymorphism analysis (the presence of wild-type or deletion alleles) was performed on genomic DNA extracted (QIAamp DNA blood mini kit; Qiagen NV, Venlo, the Netherlands) from peripheral blood samples using PCR amplification and agarose gel electrophoresis. The primer sequences were as 
follows: wild-type $B I M$ forward primer, $5^{\prime}$-ACTGTAAAAC GACGGCCAGTCCTCATGATGAAGGCTAACTCAA-3'; and reverse primer, 5'-ACCAGGAAACAGCTATGACCA ACCTCTGACAAGTGACCACCA-3'. For the BIM deletion polymorphism, the forward primer sequence was the same as that used for wild-type $B I M$, and the reverse sequence was 5'-ACCAGGAAACAGCTATGACCGGCACAGCCT CTATGGAGAACA-3'. The PCR conditions were $95^{\circ} \mathrm{C}$ for 3 minutes, and then 40 cycles of $94^{\circ} \mathrm{C}$ for 30 seconds, $58^{\circ} \mathrm{C}$ for 30 seconds and $72^{\circ} \mathrm{C}$ for 30 seconds. The final elongation step was performed at $72^{\circ} \mathrm{C}$ for 5 minutes. The PCR products were subjected to electrophoresis in $2 \%$ agarose gel stained with ethidium bromide and visualized using an ultraviolet illuminator.

\section{Statistical analysis}

$\mathrm{R}$ version 3.1.2 and $\mathrm{SAS}^{\circledR} 9.2$ software were used for all statistical analyses, including those in the meta-analysis. Two-sided $P$-values of less than 0.05 were considered statistically significant.

In the exploratory study, demographic and clinicopathological characteristics and adverse reactions were summarized by $B I M$ deletion polymorphism status using descriptive statistics. ORR and DCR between patients with and without BIM deletion polymorphism were compared using Pearson's Chi-square test. Survival curves were drawn by the KaplanMeier method, and statistical test was performed using log-rank test. To calculate hazard ratios (HRs) and 95\% confidence intervals (CIs), Cox regression analysis was applied among both overall population and those prespecified subgroups according to the following prognostic factors: age, gender, smoking status, type of EGFR mutation, chemotherapy history and EGFR-TKIs treatment line.

In the meta-analysis, risk ratios (RRs) for binary data (ORR and DCR) as well as HRs for survival time (PFS and OS) were pooled along with 95\% CIs using fixed-effect model and additionally displayed using forest plots. Statistical heterogeneity was considered significant when $P$-value was less than 0.10 for the $Q$-test. Publication bias was evaluated using funnel plot and Begg's and Egger's tests. ${ }^{21,22}$

\section{Results}

\section{Demographic and clinicopathological characteristics}

The relevant characteristics of the study patients at the initiation of EGFR-TKI treatment are summarized in Table 1. The median age of all the included patients was 58.5 years, $94(67.1 \%)$ patients were female and $117(83.6 \%)$ did
Table I Demographic and clinicopathological characteristics of the patients included in cohort study

\begin{tabular}{|c|c|c|c|}
\hline \multirow[t]{2}{*}{ Characteristic } & \multicolumn{2}{|c|}{ BIM deletion status } & \multirow{2}{*}{$\begin{array}{l}\text { All } \\
(N=140)\end{array}$} \\
\hline & $\begin{array}{l}\text { Heterozygous } \\
(\mathrm{N}=37)\end{array}$ & $\begin{array}{l}\text { Wild type } \\
(\mathrm{N}=103)\end{array}$ & \\
\hline \multicolumn{4}{|l|}{ Age (years) } \\
\hline Mean (SD) & $56.1(11.05)$ & $58.5(9.72)$ & $57.9(10.11)$ \\
\hline Median & 56.3 & 58.9 & 58.5 \\
\hline$<65$ & $28(75.7)$ & $75(72.8)$ & $103(73.6)$ \\
\hline$\geq 65$ & $9(24.3)$ & $28(27.2)$ & $37(26.4)$ \\
\hline \multicolumn{4}{|l|}{ Gender } \\
\hline Male & $8(21.6)$ & $38(36.9)$ & $46(32.9)$ \\
\hline Female & $29(78.4)$ & $65(63.1)$ & $94(67.1)$ \\
\hline \multicolumn{4}{|c|}{ Family history of lung cancer } \\
\hline No & $33(89.2)$ & $84(81.6)$ & 117 (83.6) \\
\hline Yes & $4(10.8)$ & $19(18.4)$ & $23(16.4)$ \\
\hline \multicolumn{4}{|l|}{ Smoking } \\
\hline No & $30(81.1)$ & $76(73.8)$ & $106(75.7)$ \\
\hline Yes & $7(18.9)$ & $27(26.2)$ & $34(24.3)$ \\
\hline \multicolumn{4}{|l|}{ Radical surgery } \\
\hline No & $22(59.5)$ & $74(71.8)$ & $96(68.6)$ \\
\hline Yes & $15(40.5)$ & $29(28.2)$ & $44(31.4)$ \\
\hline \multicolumn{4}{|c|}{ ECOG performance status } \\
\hline 0 & $4(10.8)$ & $6(5.8)$ & $10(7.1)$ \\
\hline I & $29(78.4)$ & $92(89.3)$ & $12 \mid(86.4)$ \\
\hline 2 & $4(10.8)$ & $5(4.9)$ & $9(6.4)$ \\
\hline \multicolumn{4}{|l|}{ Histology } \\
\hline Adenocarcinoma & $33(89.2)$ & $95(92.2)$ & |28 (9|.4) \\
\hline Other & $4(10.8)$ & $8(7.8)$ & $12(8.6)$ \\
\hline \multicolumn{4}{|c|}{ Number of metastatic organs* } \\
\hline$\leq 2$ & $26(70.3)$ & $68(66.7)$ & $94(67.6)$ \\
\hline$>2$ & II (29.7) & $34(33.3)$ & $45(32.4)$ \\
\hline \multicolumn{4}{|l|}{ EGFR mutation } \\
\hline 18 mutation & I (2.7) & $3(2.9)$ & $4(2.9)$ \\
\hline 19 mutation & $22(59.5)$ & $51(49.5)$ & $73(52.1)$ \\
\hline 20 mutation & $2(5.4)$ & $2(1.9)$ & $4(2.9)$ \\
\hline 21 mutation & $12(32.4)$ & $47(45.6)$ & $59(42.1)$ \\
\hline \multicolumn{4}{|l|}{ Clinical stage } \\
\hline III & $4(10.8)$ & $5(4.9)$ & $9(5.4)$ \\
\hline IV & $33(89.2)$ & $98(95.1)$ & |3| (93.6) \\
\hline \multicolumn{4}{|l|}{ EGFR-TKIs treatment } \\
\hline First line & $12(32.4)$ & $42(40.8)$ & $54(38.6)$ \\
\hline Second or more line & $25(67.6)$ & 61 (59.2) & $86(6 I .4)$ \\
\hline
\end{tabular}

Notes: Data presented as $\mathrm{n}(\%)$ unless stated otherwise. *Data missing for one patient. Abbreviations: ECOG, Eastern Cooperative Oncology Group; EGFR, epidermal growth factor receptor; TKIs, tyrosine kinase inhibitors; SD, standard deviation.

not report family history of lung cancer. Approximately three-fourths of patients were nonsmokers and could not undergo radical surgery as well. These patients had previously received a median number of four treatment cycles. The vast majority of patients had an Eastern Cooperative Oncology Group (ECOG) performance status of 1 (86.4\%) and the pathological diagnosis of adenocarcinoma (91.4\%). In addition, there were 54 (38.6\%) patients receiving EGFR-TKIs as first-line treatment. The most common EGFR mutation was seen in exon 19 , accounting for $52.1 \%$ of mutations, followed 
by exon 21 mutation (42.1\%). In this cohort, 37 (26.4\%) patients were identified with heterozygous (eg, positive) $B I M$ deletion polymorphism.

\section{Clinical responses and survival}

We analyzed the association between the BIM deletion polymorphism status and clinical outcomes. In total, 133 patients were eligible for response assessment. The ORR and DCR in patients with heterozygous $B I M$ deletion and treated with an EGFR-TKI were $48.5 \%$ (95\% CI: $30.8 \%-66.5 \%$ ) and 93.9\% (95\% CI: 79.8\%-99.3\%), respectively, which were not significantly different from those $(63.0 \%$ [95\% CI: $52.8 \%-$ 72.4\%] and 97.0\% [95\% CI: 91.5\%-99.4\%], respectively) observed in patients without the $B I M$ deletion $(P=0.16$ and $P=0.60$, respectively) (Table 2 ).

The median follow-up duration was 29 months (range 2-61) for the entire patient cohort. At the time of the data analysis, 125 patients developed disease progression, including $32(86.5 \%)$ in the heterozygous BIM deletion group and $93(90.3 \%)$ in the wild-type group. The median PFS was 21 months (95\% CI: 12-22) for patients with heterozygous $B I M$ deletion polymorphism and 17 months (95\% CI: 12-19) for the wild-type population. The Kaplan-Meier curve for PFS showed no significant difference between the heterozygous and wild type population after EGFR-TKIs therapy ( $P=0.27$; Figure $1 \mathrm{~A})$. The possible predictive factors of EGFR-TKIs treatment efficacy in terms of PFS were further investigated using prespecified subgroups (Table 3). Each subgroup analysis showed patients with or without the deletion polymorphism did not differ on PFS. Seventyeight patients $(55.7 \%)$ died, including $24(64.9 \%)$ in the

Table 2 Clinical response and adverse reactions after EGFRTKls therapy in cohort study

\begin{tabular}{clll}
\hline & \multicolumn{2}{l}{ BIM deletion status } & P-value \\
\cline { 2 - 3 } & $\begin{array}{l}\text { Heterozygous } \\
\mathbf{( N = 3 7 )}\end{array}$ & $\begin{array}{l}\text { Wild type } \\
\mathbf{( N = 1 0 3 )}\end{array}$ & \\
\hline Clinical response, n (\%) & $16(48.5)$ & $63(63.0)$ & 0.16 \\
ORR & $30.8-66.5$ & $52.8-72.4$ & \\
$95 \%$ Cl & $31(93.9)$ & $97(97.0)$ & 0.60 \\
DCR & $79.8-99.3$ & $91.5-99.4$ & \\
$95 \%$ Cl & $18(48.6)$ & $55(53.4)$ & \\
Any adverse events, $\mathrm{n}(\%)$ & $16(43.2)$ & $50(48.5)$ & \\
Rash & $7(18.9)$ & $10(9.7)$ & \\
Diarrhea & $4(10.8)$ & $13(12.6)$ & \\
Liver function impaired & $2(5.4)$ & $2(1.9)$ & \\
Paronychia & 0 & $3(2.9)$ & \\
Epistaxis & &
\end{tabular}

Abbreviations: $\mathrm{Cl}$, confidence interval; $\mathrm{DCR}$, disease control rate; EGFR, epidermal growth factor receptor; ORR, objective response rate; TKIs, tyrosine kinase inhibitors. heterozygous BIM deletion group and $54(52.4 \%)$ in the wild-type group. The median OS was 34 months for patients with the BIM deletion and 33 months for those without the $B I M$ deletion $(P=0.61$; Figure $1 \mathrm{~B})$. The median OS was also not significantly different between the heterozygous $B I M$ and wild-type groups ( $P=0.61$; Figure 1B). Furthermore, no significant differences in OS were found between patients with or without the deletion polymorphism with respect to selected patient subgroups (Table 4).

\section{Adverse reactions}

The study patients after EGFR-TKI treatment had similar adverse reactions of all types regardless of their $B I M$ deletion polymorphism status ( $48.6 \%$ [heterozygous] vs $53.4 \%$ [wild type]). Rash and diarrhea were the most reported adverse reactions (Table 2).

\section{Meta-analysis of BIM deletion status and clinical outcomes}

One hundred sixty-nine records were identified in PubMed (from 1965 to November 2015), Embase (from 1965 to November 2015) and Cochrane Library databases according to the search strategy that used key words associated with "Lung cancer", "BIM or (BCL2L11 deletion) or (Bcl-2like protein 11 deletion)" and "EGFR-mutant or (epidermal growth factor receptor mutation) or EGFR" without language limit. Finally, nine eligible previous cohort studies, ${ }^{15,23-30}$ together with our present cohort study, were included for the meta-analysis, which involved a total of 1,317 NSCLC patients with $E G F R$ mutations that referred to the efficacy of EGFR-TKIs (gefitinib, erlotinib or afatinib) stratified by BIM polymorphism status. The flow chart of study selection is summarized in Figure S1, and the characteristics of all the studies included in the meta-analysis are presented in Table S1. All of the ten studies presented HR of PFS data for pooling; nonetheless, data of ORR, DCR and OS were not available in several distinct studies, and so they were excluded from their respective pooling. Study quality was assessed by using the Newcastle-Ottawa Scale. ${ }^{31}$ In general, the overall quality of included cohort studies could be rated as good (data not shown). Funnel plots (Figure S2), Egger's tests and Begg's test with regard to PFS indicated potential publication bias (Egger's $P=0.02$; Begg's $P=0.02$ ). Given the absence of heterogeneity $(Q[\mathrm{df}=9]=8.78 ; P=0.46)$ in the ten included studies, the results of fixed-effects models were used to draw study conclusions.

In the ten included studies, the positive BIM polymorphism did not show a completely consistent effect on PFS 


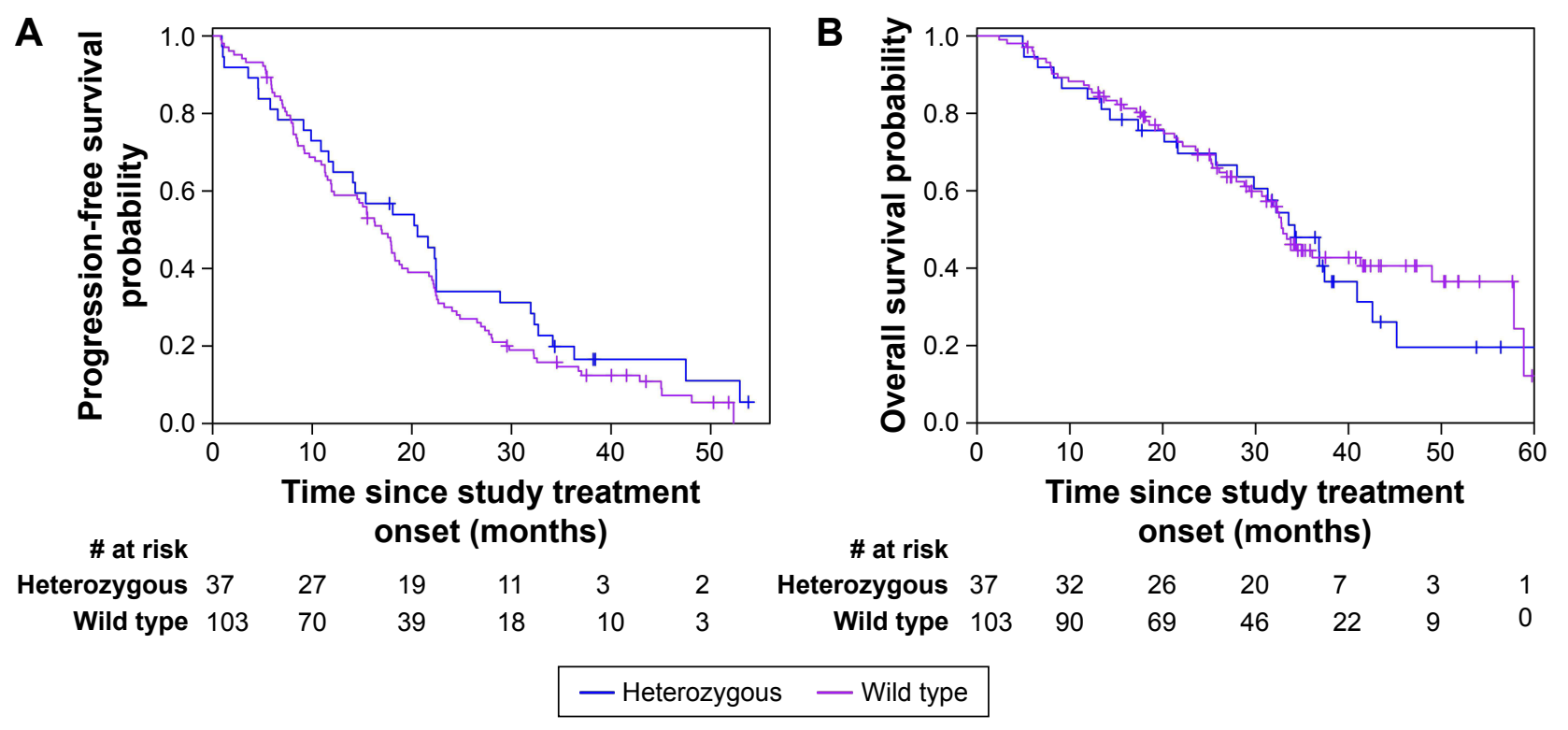

Figure I Kaplan-Meier curves for (A) progression-free survival and (B) overall survival according to BIM deletion status.

(Figure 2A). With a large sample size after pooling, however, a significant difference was then found between patients with or without the deletion polymorphism $(\mathrm{HR}=1.45,95 \% \mathrm{CI}$ : 1.06-1.99; $P=0.02$; Figure 2A). However, such difference was not observed in terms of OS (HR $=1.23,95 \% \mathrm{CI}$ : 0.74-2.05; $P=0.43$; Figure 2B), ORR (RR $=0.90,95 \% \mathrm{CI}$ : $0.55-1.48 ; P=0.69$; Figure 2C) and DCR (RR =0.99, 95\% CI: 0.93-1.05; $P=0.64$; Figure 2D).

\section{Discussion}

To the best of our knowledge, the predictive role of BIM deletion polymorphism in efficacy of EGFR-TKIs among NSCLC patients with $E G F R$ mutations remains elusive. BIM deletion polymorphism is only found in East Asian descent. ${ }^{15}$ A recent study randomly selected a wide range of 6,858 participants and used real-time PCR assay with high-resolution melting to detect BIM and EGFR mutation. The results showed that

Table 3 Progression-free survival analysis in patient subgroups according to BIM deletion status

\begin{tabular}{|c|c|c|c|c|}
\hline \multirow[t]{2}{*}{ Subgroup } & \multirow{2}{*}{$\begin{array}{l}\text { Number } \\
\text { of patients }\end{array}$} & \multicolumn{2}{|c|}{ Number of events (\%) } & \multirow{2}{*}{$\begin{array}{l}\text { Hazard ratio } \\
(95 \% \mathrm{CI})\end{array}$} \\
\hline & & Heterozygous & Wild type & \\
\hline Overall & 140 & $32(86.5)$ & $93(90.3)$ & $0.80(0.53-1.20)$ \\
\hline \multicolumn{5}{|l|}{ Age (years) } \\
\hline$\leq 65$ & 103 & $24(85.7)$ & $68(90.7)$ & $0.80(0.50-1.29)$ \\
\hline$>65$ & 37 & $8(88.9)$ & $25(89.3)$ & $0.74(0.33-1.66)$ \\
\hline \multicolumn{5}{|l|}{ Gender } \\
\hline Male & 46 & $7(87.5)$ & $36(94.7)$ & $0.4 \mid(0.17-1.01)$ \\
\hline Female & 94 & $25(86.2)$ & $57(87.7)$ & $0.98(0.6 \mathrm{I}-1.59)$ \\
\hline \multicolumn{5}{|l|}{ Smoking } \\
\hline No & 106 & $26(86.7)$ & $69(90.8)$ & $0.90(0.57-1.43)$ \\
\hline Yes & 34 & $6(85.7)$ & $24(88.9)$ & $0.53(0.2 \mathrm{I}-\mathrm{I} .33)$ \\
\hline \multicolumn{5}{|l|}{ EGFR mutation } \\
\hline Exon 19 & 73 & I8 (8I.8) & $46(90.2)$ & $0.73(0.42-1.29)$ \\
\hline Exon 21 & 59 & $12(100)$ & $42(89.4)$ & $1.16(0.6 I-2.2 I)$ \\
\hline Others & 8 & $2(66.7)$ & $5(100)$ & $0.49(0.09-2.67)$ \\
\hline \multicolumn{5}{|l|}{ Prior chemotherapy } \\
\hline No & 39 & $7(100)$ & $30(93.8)$ & $\mathrm{I} .00(0.42-2.43)$ \\
\hline Yes & 101 & $25(83.3)$ & $63(88.7)$ & $0.74(0.46-1.17)$ \\
\hline \multicolumn{5}{|l|}{ EGFR-TKIs treatment } \\
\hline First line & 54 & II (9I.7) & $39(92.9)$ & $0.96(0.48-1.92)$ \\
\hline Second or more line & 86 & $21(84.0)$ & $54(88.5)$ & $0.73(0.44-1.22)$ \\
\hline
\end{tabular}

Abbreviations: $\mathrm{Cl}$, confidence interval; EGFR, epidermal growth factor receptor; TKIs, tyrosine kinase inhibitors. 
Table 4 Overall survival analysis in patient subgroups according to BIM deletion status

\begin{tabular}{|c|c|c|c|c|}
\hline \multirow[t]{2}{*}{ Subgroup } & \multirow{2}{*}{$\begin{array}{l}\text { Number } \\
\text { of patients }\end{array}$} & \multicolumn{2}{|c|}{ Number of events (\%) } & \multirow{2}{*}{$\begin{array}{l}\text { Hazard ratio } \\
(95 \% \mathrm{Cl})\end{array}$} \\
\hline & & Heterozygous & Wild type & \\
\hline Overall & 140 & $24(64.9)$ & $54(52.4)$ & I.I4 (0.70-I.84) \\
\hline \multicolumn{5}{|l|}{ Age (years) } \\
\hline$\leq 65$ & 103 & $17(60.7)$ & $38(50.7)$ & $1.18(0.66-2.09)$ \\
\hline$>65$ & 37 & $7(77.8)$ & $16(57.1)$ & $0.94(0.38-2.32)$ \\
\hline \multicolumn{5}{|l|}{ Gender } \\
\hline Male & 46 & $5(62.5)$ & $25(65.8)$ & $0.59(0.22-1.57)$ \\
\hline Female & 94 & $19(65.5)$ & $29(44.6)$ & $1.64(0.91-2.95)$ \\
\hline \multicolumn{5}{|l|}{ Smoking } \\
\hline No & 106 & $20(66.7)$ & $36(47.4)$ & $1.52(0.87-2.63)$ \\
\hline Yes & 34 & $4(57.1)$ & $18(66.7)$ & $0.50(0.16-1.50)$ \\
\hline \multicolumn{5}{|l|}{ EGFR mutation } \\
\hline Exon 19 & 73 & $14(63.6)$ & $2 \mid(4 I .2)$ & $1.49(0.76-2.93)$ \\
\hline Exon 21 & 59 & $8(66.7)$ & $30(63.8)$ & $0.87(0.40-1.91)$ \\
\hline Others & 8 & $2(66.7)$ & $3(60.0)$ & $1.21(0.16-9.34)$ \\
\hline \multicolumn{5}{|l|}{ Prior chemotherapy } \\
\hline No & 39 & $6(85.7)$ & $18(56.3)$ & $1.44(0.57-3.67)$ \\
\hline Yes & 101 & $18(60.0)$ & $36(50.7)$ & $1.06(0.60-1.86)$ \\
\hline \multicolumn{5}{|l|}{ EGFR-TKIs treatment } \\
\hline First line & 54 & $10(83.3)$ & $24(57.1)$ & $1.56(0.74-3.28)$ \\
\hline Second or more line & 86 & $14(56.0)$ & $30(49.2)$ & $0.98(0.52-1.86)$ \\
\hline
\end{tabular}

Abbreviations: $\mathrm{Cl}$, confidence interval; EGFR, epidermal growth factor receptor; TKIs, tyrosine kinase inhibitors.

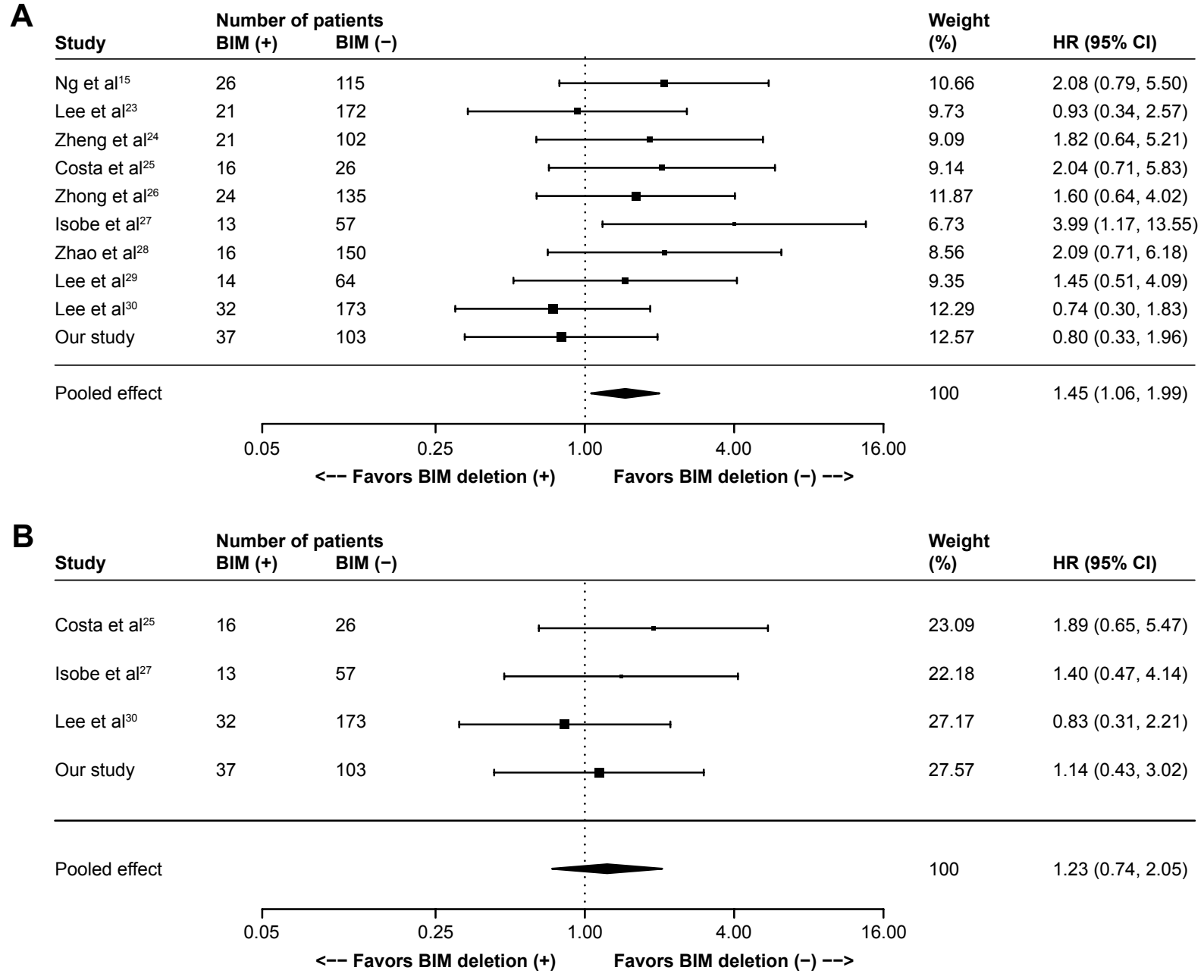

Figure 2 (Continued) 


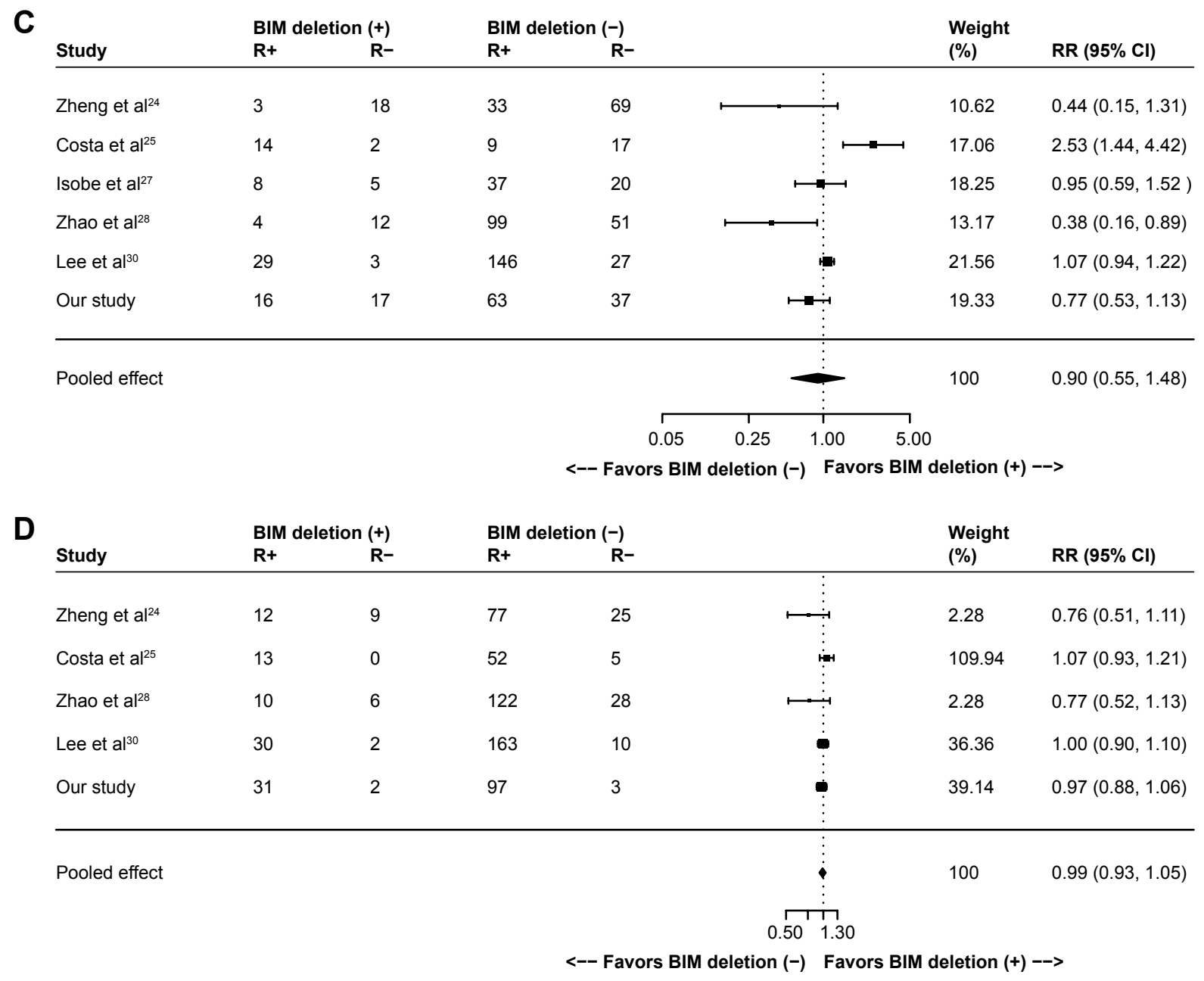

Figure 2 Meta-analyses of (A) PFS, (B) OS, (C) ORR and (D) DCR according to BIM deletion status in EGFR-mutant non-small-cell lung cancer patients receiving EGFR-TKIs. $(\mathbf{C}$ and $\mathbf{D}) \mathrm{R}+$ represents responders and $\mathrm{R}$ - represents nonresponders.

Abbreviations: $\mathrm{Cl}$, confidence interval; DCR, disease control rate; EGFR, epidermal growth factor receptor; HR, hazard ratio; ORR, objective response rate; OS, overall survival; PFS, progression-free survival; RR, relative risk; TKIs, tyrosine kinase inhibitors.

there were four outcomes of BIM: non-detection of 2,903 bp $B I M$ (NA), non-deletion of 2,903 bp BIM (homozygous non-deletion-type DNA, II), 2,903 bp deletion BIM (homozygous deletion-type DNA, DD) and heterozygote (ID). ${ }^{32} \mathrm{We}$ conducted our present study in the People's Republic of China to investigate whether the $B I M$ polymorphism status would affect clinical efficacy of EFGR-TKIs and prognosis of NSCLC patients with EGFR mutations treated with EFGR-TKIs. Furthermore, we included all of the eligible cohort studies or appropriate subgroups of cohort studies in our meta-analysis to achieve an adequate sample size to draw a reliable conclusion. The present exploratory cohort study did not show positive BIM deletion was associated with poorer clinical outcomes in advanced and metastatic NSCLC patients after EGFR-TKIs treatment. With a substantially expanded sample size $(n=1,317)$ in the current meta-analysis, however, the positive $B I M$ deletion displayed significant predictive effects on shorter PFS $(P=0.02)$, while it failed to demonstrate significant difference regarding the other three common clinical outcome measures OS $(P=0.43)$, ORR $(P=0.69)$ and DCR $(P=0.64)$.

In our cohort, the positive BIM deletion polymorphism occurred in 37 (26.4\%) patients, which is relatively higher than the rate $(9.6 \%-20 \%)$ reported in other cohort studies included for meta-analysis, ${ }^{15,23,24,26-30}$ except for one study which has also quantitatively reported low/intermediate $B I M$ mRNA expression. ${ }^{25}$ The characteristics of the patients at baseline indicated that our cohort patients with heterozygous $B I M$ deletion polymorphism were likely associated with marginally better prognosis factors in terms of younger age, less smoking, better performance status, less metastasis and earlier disease stage as of TKIs treatment onset. These slight inequalities of distribution may partially contribute to the estimated HR of $<1$ observed for PFS (HR $=0.80$; with vs without $B I M$ deletion polymorphism). Even so, similar observation of variants was reported in two published 
studies conducted in Korea $(\mathrm{HR}=0.74,95 \% \mathrm{CI}: 0.30-1.83$; $\mathrm{HR}=0.93$, 95\% CI: $0.34-2.57$, respectively). ${ }^{23,30}$ The authors of these studies and Chinese counterparts ${ }^{9}$ discussed these findings using the following potential arguments: (1) uncertainties may be by chance due to small size of included study patients; (2) they did not consider other proapoptotic Bcl-2 family members such as BAX, BAK, and other BH3-only proteins including BAD and PUMA which might be key players in the apoptotic response in oncogene-addicted cancer; (3) unconsidered concomitant genetic alterations beyond $E G F R$ mutations could conceivably accelerate or delay cancer progression; and (4) BIM RNA levels in treatmentnaïve tissue were not measured; these measurements could be helpful for better understanding of the meaning of BIM deletion in patients with EGFR-mutant NSCLC. All of these highlighted points were echoed in our current study indeed. Subject to limited number of included studies and data availability, our study did not further analyze the role of $E G F R$ subtypes with $B I M$ polymorphism in predicting efficacy of EGFR-TKIs, either. Nevertheless, we analyzed toxic effects and obtained similar findings, with rash and diarrhea being the most common adverse reactions as in the EGFR-TKI group of the randomized control trials. ${ }^{4,5,7,8}$

Several prior studies ${ }^{15,24-29}$ reported that patients with BIM deletion polymorphism had significantly shorter PFS after EGFR-TKI treatment than did patients without BIM deletion polymorphism. As a result, our meta-analysis of these studies also reflected this finding. Although several previous meta-analyses ${ }^{9,33-36}$ mentioned similar findings regarding PFS, the current pooled analysis containing more eligible studies further provided a possibility to analyze other clinical outcome measures. As a comprehensive meta-analysis of PFS, OS, ORR and DCR with the largest sample size to date, our study provided a more reliable answer regarding the impact of BIM polymorphism status on treatment efficacy of EGFR-TKIs in advanced and metastatic NSCLC patients with EGFR mutations.

Despite the comprehensive findings, there exist several limitations in our cohort study and meta-analysis. First, unlike randomized controlled trials, this present observational study, especially of small sample size, predisposes to imbalanced distribution of baseline characteristics. In this case, we did a serial of subgroup analyses to ascertain possibly consistent effect. In addition, the data of the cohort study are from a single hospital in the People's Republic of China, which would potentially limit any extrapolations of the study conclusions. For the part of meta-analysis, reported aggregate data from several cohort studies were used rather than individual patient data, which may not provide robust estimation for the comparative efficacy. Publication bias might exist, although we did citations search without any language limit. Moreover, the quality of meta-analysis was subject to the quality of individual studies included. Second, although the prevalence of BIM deletion polymorphism was examined carefully in this study, we did not consider other coexisting genetic alterations beyond that of BIM deletion polymorphism. The underlying biology of EGFRmutant NSCLC and tumor prognosis should be complex enough. $3,9,37,38$ Therefore, more efforts should be made to investigate the potential mechanisms of the primary and secondary resistance to EGFR-TKIs induced by BIM polymorphism and other ones in order to find oriented solutions and develop new therapies.

In summary, our meta-analysis of studies demonstrated that $B I M$ deletion polymorphism is associated with shorter PFS after EGFR-TKIs treatment in advanced NSCLC EGFRmutant patients than those without BIM polymorphism. Even so, additional large multicenter well-designed cohort studies comprising essential BIM gene alteration and other concurrent genetic alterations are warranted to uncover more underlying biology of EGFR-mutant NSCLC used for predicting clinical prognosis in the future. This further clarification will provide benefits for new drug development in the relevant therapeutic area.

\section{Acknowledgments}

This work was supported by grants from the National Natural Science Foundation of China (81401892), Shanghai Health Bureau Foundation (201440423) and the Program for Cooperation among Industry, Academy, and Research, the Committee of Science and Technology, Baoshan District, Shanghai (No bkw2014122). The authors thank Sam Zhong for his generous assistance with this study.

\section{Disclosure}

The authors report no conflicts of interest in this work.

\section{References}

1. Chen W, Zheng R, Baade PD, et al. Cancer statistics in China, 2015. CA Cancer J Clin. 2016;66(2):115-132.

2. Costa DB, Halmos B, Kumar A, et al. BIM mediates EGFR tyrosine kinase inhibitor-induced apoptosis in lung cancers with oncogenic EGFR mutations. PLoS Med. 2007;4(10):1669-1679; discussion 1680.

3. Ni J, Zhang L. Evaluation of three small molecular drugs for targeted therapy to treat nonsmall cell lung cancer. Chin Med J (Engl). 2016; 129(3):332-340.

4. Maemondo M, Inoue A, Kobayashi K, et al; North-East Japan Study Group. Gefitinib or chemotherapy for non-small-cell lung cancer with mutated EGFR. N Engl J Med. 2010;362(25):2380-2388. 
5. Mok TS, Wu YL, Thongprasert S, et al. Gefitinib or carboplatinpaclitaxel in pulmonary adenocarcinoma. NEngl J Med. 2009;361(10): 947-957.

6. Aoki T, Igawa S, Furuya N, et al. Impacts of treatment lines and initiation timing of erlotinib for advanced non-small cell lung cancer. Anticancer Res. 2012;32(2):601-608.

7. Mitsudomi T, Morita S, Yatabe Y, et al; West Japan Oncology Group. Gefitinib versus cisplatin plus docetaxel in patients with non-small-cell lung cancer harboring mutations of the epidermal growth factor receptor (WJTOG3405): an open label, randomised phase 3 trial. Lancet Oncol. 2010;11(2):121-128.

8. Zhou C, Wu YL, Chen G, et al. Erlotinib versus chemotherapy as first-line treatment for patients with advanced EGFR mutation-positive non-small-cell lung cancer (OPTIMAL, CTONG-0802): a multicentre, open-label, randomised, phase 3 study. Lancet Oncol. 2011;12(8): 735-742.

9. Huang WF, Liu AH, Zhao HJ, Dong HM, Liu LY, Cai SX. BIM gene polymorphism lowers the efficacy of EGFR-TKIs in advanced non small cell lung cancer with sensitive EGFR mutations: a systematic review and meta-analysis. Medicine (Baltimore). 2015;94(33):e1263.

10. Pao W, Chmielecki J. Rational, biologically based treatment of EGFRmutant non-small-cell lung cancer. Nat Rev Cancer. 2010;10(11): 760-774.

11. Forde PM, Ettinger DS. Managing acquired resistance in EGFRmutated non-small cell lung cancer. Clin Adv Hematol Oncol. 2015; 13(8):528-532.

12. Wang S, Cang S, Liu D. Third-generation inhibitors targeting EGFR T790M mutation in advanced non-small cell lung cancer. J Hematol Oncol. 2016;9:34.

13. Wang S, Tsui ST, Liu C, Song Y, Liu D. EGFR C797S mutation mediates resistance to third-generation inhibitors in T790M-positive non-small cell lung cancer. J Hematol Oncol. 2016;9(1):59.

14. Wang S, Song Y, Yan F, Liu D. Mechanisms of resistance to thirdgeneration EGFR tyrosine kinase inhibitors. Front Med. 2016;10(4): 383-388.

15. Ng KP, Hillmer AM, Chuah CT, et al. A common BIM deletion polymorphism mediates intrinsic resistance and inferior responses to tyrosine kinase inhibitors in cancer. Nat Med. 2012;18(4):521-528.

16. O'Connor L, Strasser A, O'Reilly LA, et al. Bim: a novel member of the Bcl-2 family that promotes apoptosis. EMBO J. 1998;17(2):384-395.

17. Nakagawa T, Takeuchi S, Yamada T, et al. EGFR-TKI resistance due to BIM polymorphism can be circumvented in combination with HDAC inhibition. Cancer Res. 2013;73(8):2428-2434.

18. Eisenhauer EA, Therasse P, Bogaerts J, et al. New response evaluation criteria in solid tumours: revised RECIST guideline (version 1.1). Eur J Cancer. 2009;45(2):228-247.

19. Paez JG, Jänne PA, Lee JC, et al. EGFR mutations in lung cancer: correlation with clinical response to gefitinib therapy. Science. 2004; 304(5676):1497-1500.

20. Yi S, Zhuang Y, Zhou J, et al. A comparison of epidermal growth factor receptor mutation testing methods in different tissue types in non-small cell lung cancer. Int J Mol Med. 2014;34(2):464-474.

21. Begg CB, Mazumdar M. Operating characteristics of a rank correlation test for publication bias. Biometrics. 1994;50(4):1088-1101.

22. Egger M, Davey Smith G, Schneider M, Minder C. Bias in meta-analysis detected by a simple, graphical test. BMJ. 1997;315(7109):629-634.

23. Lee JK, Shin JY, Kim S, et al. Primary resistance to epidermal growth factor receptor (EGFR) tyrosine kinase inhibitors (TKIs) in patients with non-small-cell lung cancer harboring TKI-sensitive EGFR mutations: an exploratory study. Ann Oncol. 2013;24(8):2080-2087.
24. Zheng L, Lin B, Song Z, et al. [Relationship between BIM gene polymorphism and therapeutic efficacy in the retreatment of advanced non-small cell lung cancer with tyrosine kinase inhibitor]. Zhongguo Fei Ai Za Zhi. 2013;16(12):632-638. Chinese [with English abstract].

25. Costa C, Molina MA, Drozdowskyj A, et al. The impact of EGFR T790M mutations and BIM mRNA expression on outcome in patients with EGFR-mutant NSCLC treated with erlotinib or chemotherapy in the randomized phase III EURTAC trial. Clin Cancer Res. 2014;20(7):2001-2010.

26. Zhong J, Li ZX, Zhao J, et al. Analysis of BIM (BCL-2 like 11 gene) deletion polymorphism in Chinese non-small cell lung cancer patients. Thorac Cancer. 2014;5(6):509-516.

27. Isobe $\mathrm{K}$, Hata $\mathrm{Y}$, Tochigi N, et al. Clinical significance of BIM deletion polymorphism in non-small-cell lung cancer with epidermal growth factor receptor mutation. J Thorac Oncol. 2014;9(4):483-487.

28. Zhao M, Zhang Y, Cai W, et al. The Bim deletion polymorphism clinical profile and its relation with tyrosine kinase inhibitor resistance in Chinese patients with non-small cell lung cancer. Cancer. 2014; 120(15):2299-2307.

29. Lee JH, Lin YL, Hsu WH, et al. Bcl-2-like protein 11 deletion polymorphism predicts survival in advanced non-small-cell lung cancer. J Thorac Oncol. 2014;9(9):1385-1392.

30. Lee JY, Ku BM, Lim SH, et al. The BIM deletion polymorphism and its clinical implication in patients with EGFR-mutant non-small-cell lung cancer treated with EGFR tyrosine kinase inhibitors. $J$ Thorac Oncol. 2015;10(6):903-909.

31. Wells GA, Shea B, O'Connell D, et al. The Newcastle-Ottawa Scale (NOS) for assessing the quality of nonrandomized studies in metaanalyses. Ottawa, ON: Ottawa Hospital Research Institute; 2011. Available from: http://www.ohri.ca/programs/clinical_epidemiology/ oxford.htm. Accessed January 1, 2011.

32. Xia JJ, Zhao SF, Xiong LW, et al. Real-time PCR assay with high resolution melting for EGFR and BIM mutation of lung cancer. Eur Rev Med Pharmacol Sci. 2016;20(13):2805-2811.

33. Nie W, Tao X, Wei H, Chen WS, Li B. The BIM deletion polymorphism is a prognostic biomarker of EGFR-TKIs response in NSCLC: a systematic review and meta-analysis. Oncotarget. 2015;6(28): 25696-25700.

34. Zou Q, Zhan P, Lv T, Song Y. The relationship between BIM deletion polymorphism and clinical significance of epidermal growth factor receptor-mutated non-small cell lung cancer patients with epidermal growth factor receptor-tyrosine kinase inhibitor therapy: a metaanalysis. Transl Lung Cancer Res. 2015;4(6):792-796.

35. Ying HQ, Chen J, He BS, et al. The effect of BIM deletion polymorphism on intrinsic resistance and clinical outcome of cancer patient with kinase inhibitor therapy. Sci Rep. 2015;5:11348.

36. Ma JY, Yan HL, Gu W. Association between BIM deletion polymorphism and clinical outcome of EGFR-mutated NSCLC patient with EGFR-TKI therapy: a meta-analysis. J Cancer Res Ther. 2015;11(2): $397-402$.

37. Lee JY, Lim SH, Kim M, et al. Is there any predictor for clinical outcome in EGFR mutant NSCLC patients treated with EGFR TKIs? Cancer Chemother Pharmacol. 2014;73(5):1063-1070.

38. Hsiao SH, Liu HE, Lee HL, et al. Distinct clinical outcomes of non-small cell lung cancer patients with epidermal growth factor receptor (EGFR) mutations treated with EGFR tyrosine kinase inhibitors: non-responders versus responders. PLoS One. 2013;8(12):e83266. 


\section{Supplementary materials}

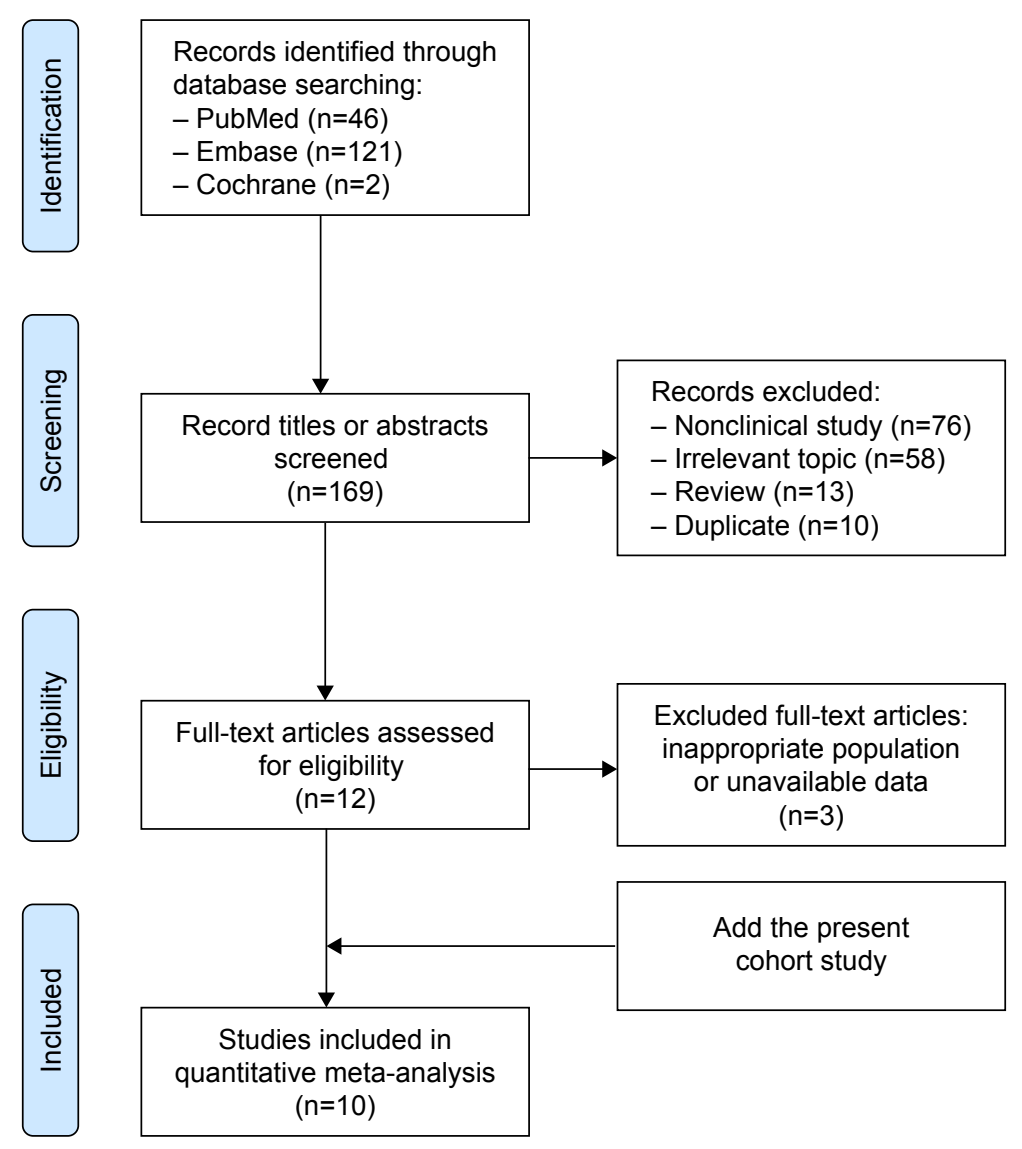

Figure SI PRISMA flow diagram of the studies search and selection process.

Abbreviation: PRISMA, preferred reporting items for systematic reviews and meta-analyses. 


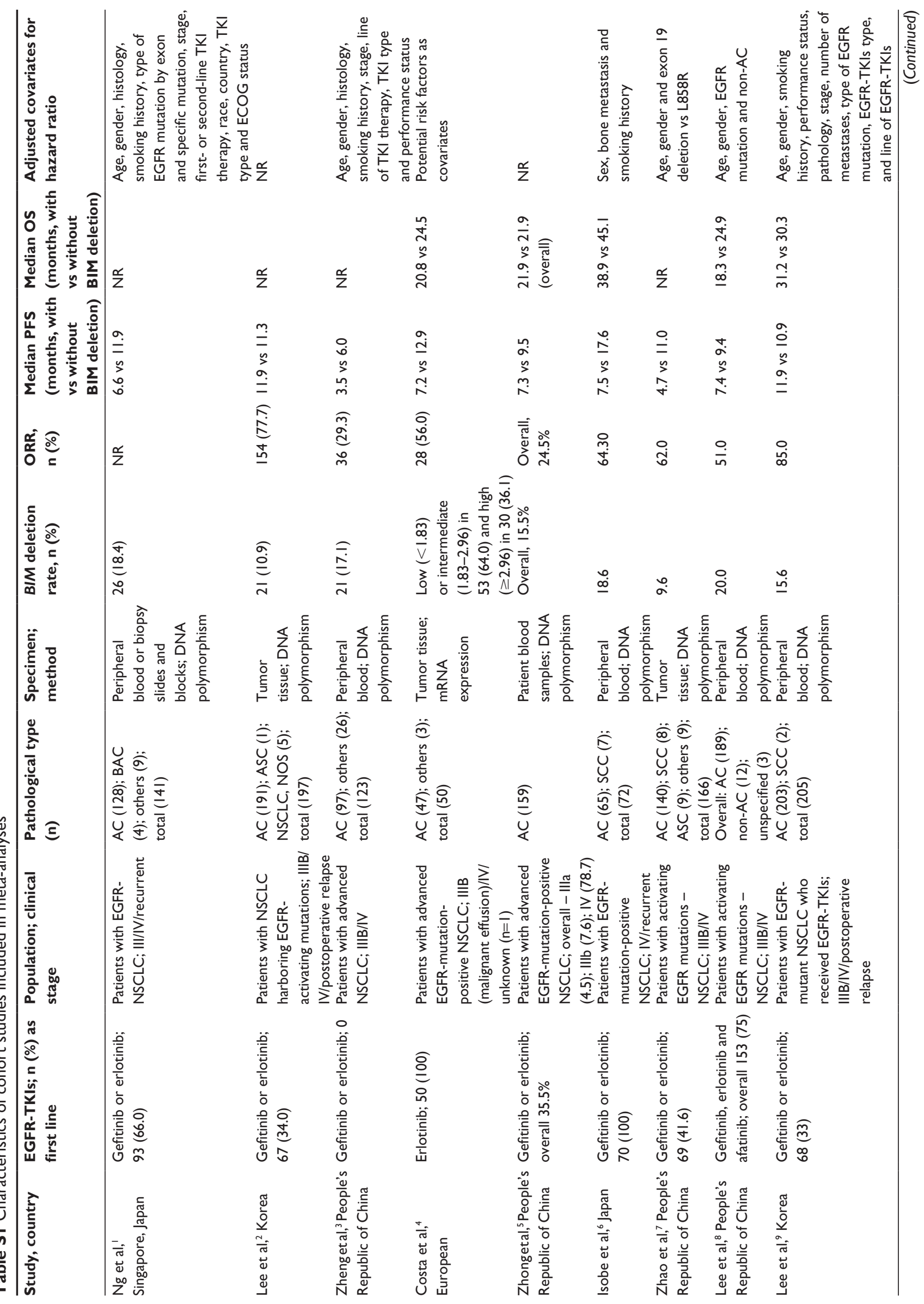



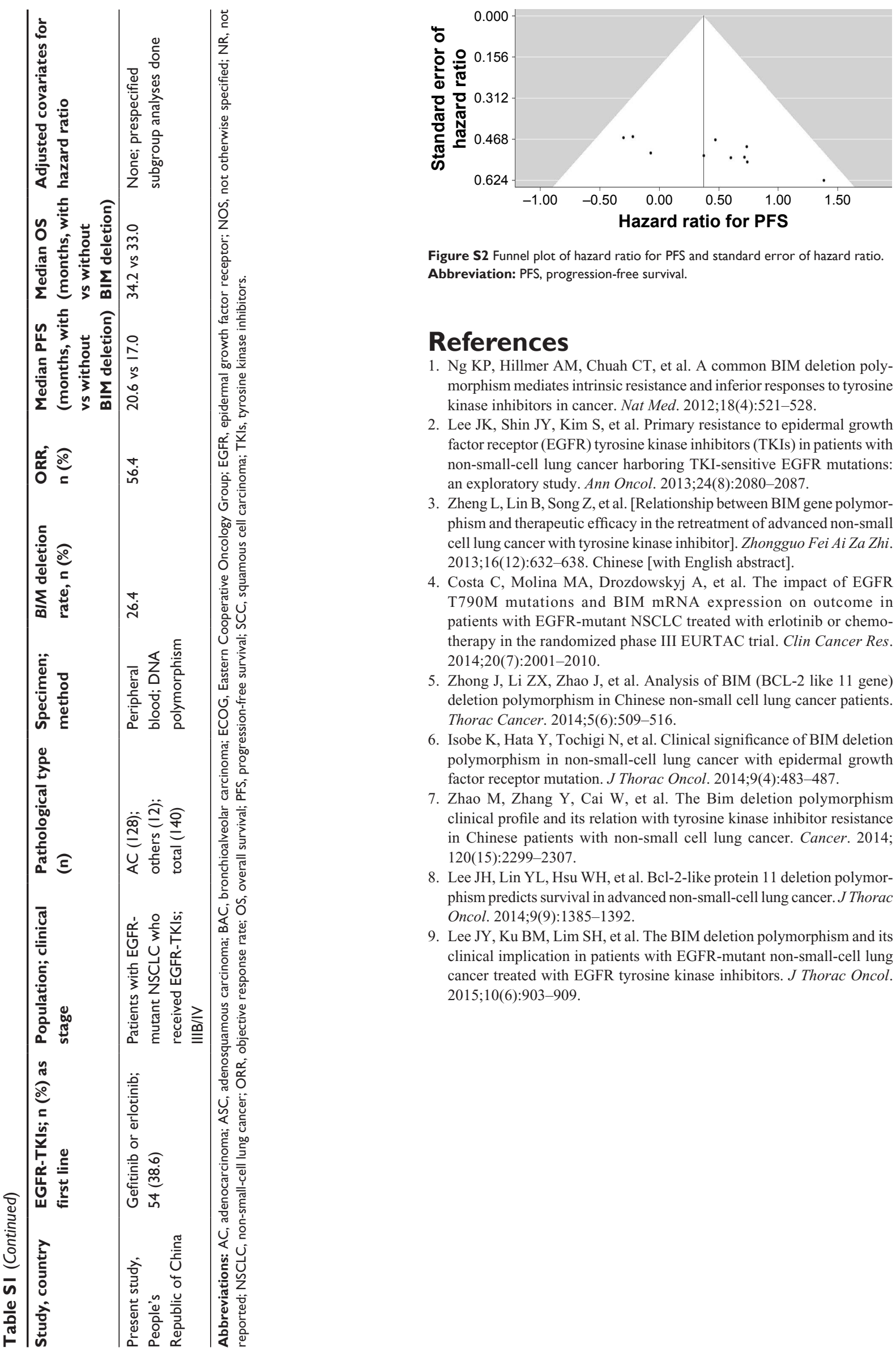

Figure S2 Funnel plot of hazard ratio for PFS and standard error of hazard ratio. Abbreviation: PFS, progression-free survival.

\section{References}

1. Ng KP, Hillmer AM, Chuah CT, et al. A common BIM deletion polymorphism mediates intrinsic resistance and inferior responses to tyrosine kinase inhibitors in cancer. Nat Med. 2012;18(4):521-528.

2. Lee JK, Shin JY, Kim S, et al. Primary resistance to epidermal growth factor receptor (EGFR) tyrosine kinase inhibitors (TKIs) in patients with non-small-cell lung cancer harboring TKI-sensitive EGFR mutations: an exploratory study. Ann Oncol. 2013;24(8):2080-2087.

3. Zheng L, Lin B, Song Z, et al. [Relationship between BIM gene polymorphism and therapeutic efficacy in the retreatment of advanced non-small cell lung cancer with tyrosine kinase inhibitor]. Zhongguo Fei Ai Za Zhi. 2013;16(12):632-638. Chinese [with English abstract].

4. Costa C, Molina MA, Drozdowskyj A, et al. The impact of EGFR T790M mutations and BIM mRNA expression on outcome in patients with EGFR-mutant NSCLC treated with erlotinib or chemotherapy in the randomized phase III EURTAC trial. Clin Cancer Res. 2014;20(7):2001-2010.

5. Zhong J, Li ZX, Zhao J, et al. Analysis of BIM (BCL-2 like 11 gene) deletion polymorphism in Chinese non-small cell lung cancer patients. Thorac Cancer. 2014;5(6):509-516.

6. Isobe $\mathrm{K}$, Hata $\mathrm{Y}$, Tochigi N, et al. Clinical significance of BIM deletion polymorphism in non-small-cell lung cancer with epidermal growth factor receptor mutation. J Thorac Oncol. 2014;9(4):483-487.

7. Zhao M, Zhang Y, Cai W, et al. The Bim deletion polymorphism clinical profile and its relation with tyrosine kinase inhibitor resistance in Chinese patients with non-small cell lung cancer. Cancer. 2014; 120(15):2299-2307.

8. Lee JH, Lin YL, Hsu WH, et al. Bcl-2-like protein 11 deletion polymorphism predicts survival in advanced non-small-cell lung cancer. $J$ Thorac Oncol. 2014;9(9):1385-1392.

9. Lee JY, Ku BM, Lim SH, et al. The BIM deletion polymorphism and its clinical implication in patients with EGFR-mutant non-small-cell lung cancer treated with EGFR tyrosine kinase inhibitors. $J$ Thorac Oncol. 2015;10(6):903-909. 
OncoTargets and Therapy

\section{Publish your work in this journal}

OncoTargets and Therapy is an international, peer-reviewed, open access journal focusing on the pathological basis of all cancers, potential targets for therapy and treatment protocols employed to improve the management of cancer patients. The journal also focuses on the impact of management programs and new therapeutic agents and protocols on

perspectives such as quality of life, adherence and satisfaction. The manuscript management system is completely online and includes a very quick and fair peer-review system, which is all easy to use. Visit http://www.dovepress.com/testimonials.php to read real quotes from published authors.

Submit your manuscript here: http://www.dovepress.com/oncotargets-and-therapy-journal 